\title{
The Long-Lasting Momentum in Weekly Returns
}

\author{
ROBERTO C. GUTIERREZ JR. and ERIC K. KELLEY*
}

\begin{abstract}
Reversal is the current stylized fact of weekly returns. However, we find that an opposing and long-lasting continuation in returns follows the well-documented brief reversal. These subsequent momentum profits are strong enough to offset the initial reversal and to produce a significant momentum effect over the full year following portfolio formation. Thus, ex post, extreme weekly returns are not too extreme. Our findings extend to weekly price movements with and without public news. In addition, there is no relation between news uncertainty and the momentum in 1-week returns.
\end{abstract}

RETURNS OF INDIVIDUAL STOCKS reverse in the short run. Lehmann (1990) and Jegadeesh (1990) find that stocks with the lowest returns over the prior week or month outperform stocks with the highest returns over the prior period. Given these findings, the literature currently views extreme weekly returns as larger than those warranted by a stock's fundamentals, due to overreaction and/or to microstructural issues. However, we find evidence suggesting that extreme weekly returns are not extreme enough: Despite the brief reversal documented by prior research, abnormal returns over the 52 weeks following an extreme weekly return are actually in the same direction as those in the extreme week. In other words, we find return momentum in a new and seemingly unexpected place-weekly returns.

While prior studies examine the performance of stocks with extreme weekly returns for only a few weeks, which is the duration of the reversal, momentum profits emerge several weeks after an extreme return and persist over the remainder of the year. The momentum that we document easily offsets the brief and initial reversal in returns. Figure 1 depicts this result (the figure is illustrative only; our statistical methods are based on calendar time, not the event time shown in the figure). Each week we construct a portfolio that is long stocks

\footnotetext{
${ }^{*}$ Gutierrez is at the Lundquist College of Business, University of Oregon. Kelley is at the Eller College of Management, University of Arizona. We thank two anonymous referees, Rob Stambaugh, Wayne Ferson, Christo Pirinsky, and seminar participants at Auburn University, Indiana University at South Bend, Rutgers University at Camden, Texas A\&M University, Texas Tech University, University of Arizona, University of Oregon, University of Utah, Washington State University, and the 2004 Financial Management Association Meetings for their comments. Special thanks go to Wes Chan for graciously providing his data on headline news and to Ekkehart Boehmer and Jerry Martin for data assistance. Kelley acknowledges financial support from the Mays Post-Doctoral Fellowship at Mays Business School, Texas A\&M University. Kelley also completed a portion of this work while on the faculty at the College of Business and Economics, Washington State University. Any errors are ours.
} 


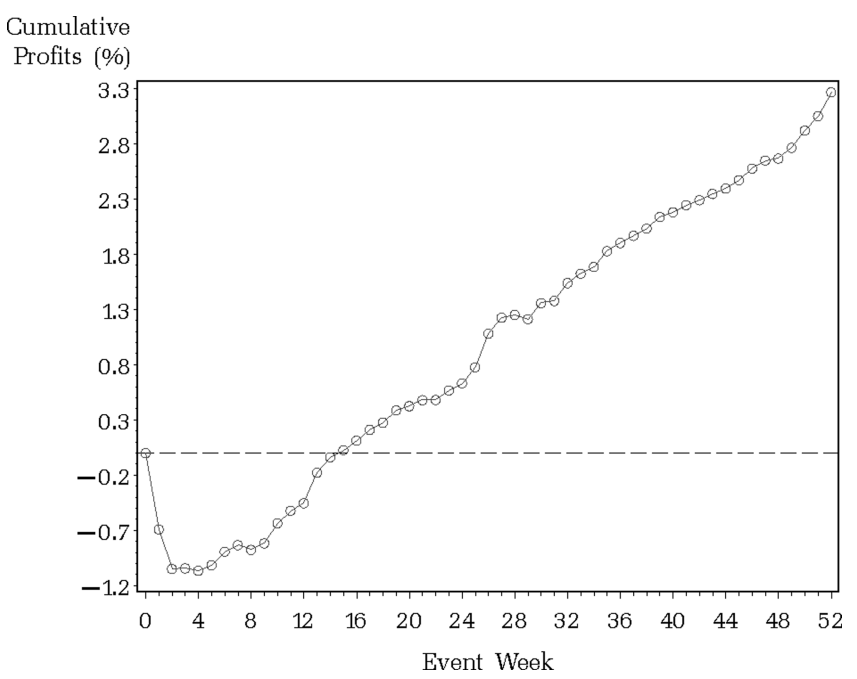

Figure 1. Each week from 1983 to 2003, we rank stocks based on their returns over the prior week and form a portfolio comprised of a long position in the top decile of stocks (winners) and a short position in the bottom decile (losers). Raw profits are calculated for each separate event week. Cumulative profits are plotted. Negative profits indicate reversal of the formation-week returns and positive profits indicate momentum. Returns are formed from the midpoints of the quoted bid and ask prices at each day's close. Stocks priced below five dollars at the end of formation week $t$ are excluded.

in the highest decile of the prior week's return and short stocks in the lowest decile. The brief reversal found by prior studies is confirmed as the profits to the long-minus-short portfolio are negative the first 2 weeks following an extreme return. The new finding is the persistent and impressive run-up in profits that follows the initial reversal. In fact, the profits over the 52 weeks following an extreme weekly return are statistically positive and over $3 \%$, a striking addition to our current understanding of extreme weekly returns. Hence, there is actually momentum in 1-week returns, net of the initial reversal.

This finding of momentum in 1-week returns complements the findings of return continuation following corporate events and firm-specific headline news and also Jegadeesh and Titman's (1993) finding of momentum in longer-horizon returns of 3-12 months. ${ }^{1}$ Given these prior findings, a lack of momentum in short-run returns essentially would be the anomaly within the anomaly literature. Comfortingly, our findings reveal momentum in returns up to 1 year

\footnotetext{
${ }^{1}$ Daniel et al. (1998) survey the evidence regarding return momentum following corporate events. Chan (2003) finds return momentum following headline news released in print media and newswires. Some concerns about the robustness of post-event return continuation exist for stock splits, dividend changes, seasoned equity offerings, and share repurchases; however, as Fama (1998) notes, the post-event drift in returns following earnings surprises stands firm. Chan (2003) provides evidence of continuation in returns following headline news controlling for many methodological concerns.
} 
to be a remarkably pervasive phenomenon. This observation should benefit researchers attempting to understand the momentum anomaly. ${ }^{2}$

Our results also provide researchers of the momentum phenomenon a new, and arguably superior, testing ground for their theories. Using weekly returns to assess potential explanations of momentum affords researchers greater confidence in identifying the news that underlies the return. The 6- or 12-month returns commonly used to examine momentum theories preclude such identification. We exploit this advantage to revisit two recent studies of the potential sources of momentum in returns. Neither Chan's (2003) finding regarding explicit and implicit news nor Zhang's (2006) finding regarding the uncertainty of news extends to the momentum in 1-week returns.

Chan (2003) provides evidence that the market underreacts to explicit news, which is firm-specific news that is publicly released, yet overreacts to implicit news, which is news implied by price changes not accompanied by any publicly released news. In contrast, we find that extreme-return stocks with explicit news and extreme-return stocks with implicit news behave similarly, both displaying short-run reversal and longer-run momentum (as in Figure 1). This finding impedes concluding that the market categorically underreacts to one type of news and overreacts to another type. Caution should therefore be exercised in modeling traders as strictly overreacting to implicit news, which is the general notion in the theories of Daniel, Hirshleifer, and Subrahmanyam (1998), Hong and Stein (1999), and Daniel and Titman (2006).

Zhang (2006) considers another potential determinant of momentum. If momentum is a consequence of psychological biases inducing traders to misreact to news, then momentum should increase with the uncertainty in the valuation impact of news. This follows from the observation that psychological biases worsen as the precision of news decreases. However, we find that the momentum in 1-week returns is not reliably related to measures of uncertainty.

Regarding the short-run reversal in returns, Jegadeesh and Titman (1995a), Cooper (1999), Subrahmanyam (2005), and others find that bid-ask bounce and other microstructural issues do not fully explain the return reversal. ${ }^{3}$ These researchers interpret the remaining reversal in returns as evidence of the market's overreaction to firm-specific news. On the other hand, Avramov, Chordia, and Goyal (2006) show that weekly reversals are strongest for stocks in which liquidity is low and turnover is high. They attribute reversal in weekly returns to price pressure caused by noninformational demand for immediacy. ${ }^{4}$ Our momentum finding does not discriminate between these two interpretations of the brief reversal. For example, it is possible that short-run traders overreact

\footnotetext{
${ }^{2}$ DeBondt and Thaler (1985) and others show that long-horizon returns of 3-5 years reverse.

${ }^{3}$ Kaul and Nimalendran (1990) and Conrad, Kaul, and Nimalendran (1991) show that part of the return reversal is due to bid-ask bounce. Lo and MacKinlay (1990) and Boudoukh, Richardson, and Whitelaw (1994) note that nonsynchronous trading contributes to contrarian profits. Jegadeesh and Titman (1995b) observe that market makers set prices in part to control their inventories, which induces a return reversal.

${ }^{4}$ Precisely measuring illiquidity is a difficult task, as Avramov et al. (2006) acknowledge. They employ Amihud's (2002) measure in their study.
} 
to news while longer-term traders underreact. Alternatively, the market might generally respond incompletely to all news while sometimes simultaneously generating sufficient price pressure to warrant a brief reversal. Understanding the precise sources of short-term reversal in returns remains a task for future research.

Regardless of the source of the reversal, our findings speak to the extant view that extreme weekly returns are too extreme. The emergence of strong and ultimately dominant momentum profits a few weeks after an extreme weekly return suggests that on average extreme weekly returns are not extreme enough. Moreover, after eliminating the spurious reversal induced by bid-ask bounce, we find that next-week reversal is largely confined to extreme-return stocks. Thus, our results show that momentum is the larger and more pervasive force in 1-week returns.

The remainder of the paper is organized as follows. Section I details our data and testing methods. Section II discusses the performance of weekly portfolios that are long winner stocks and short loser stocks, identifying momentum in 1 -week returns. Section III shows that 1 -week momentum is a new finding, independent of the longer-run momentum documented by Jegadeesh and Titman (1993). Section IV revisits Chan's (2003) and Zhang's (2006) studies using weekly returns and provides an overview of potential explanations of 1-week momentum. Section V further examines the robustness of momentum in shortrun returns. Section VI examines the relation between return consistency and the momentum in short-run returns. Section VII discusses the implications of our findings for the literature on short-run reversal. Section VIII concludes.

\section{Data and Methods}

Prior research finds reversal in the weekly returns of individual stocks. When using returns formed with transaction prices, part of this reversal is certainly due to the spurious negative correlation induced by bid-ask bounce (Roll (1984)). We eliminate this spurious reversal, as Kaul and Nimalendran (1990) and others do, by using quote data instead of transactions prices. Weekly returns are based on the midpoint of the final bid and ask quotes from Wednesday to Wednesday from 1983 through 2003. Quote data for stocks listed on NYSE and AMEX come from the Institute for the Study of Securities Markets (ISSM) for 1983 to 1992 and from the New York Stock Exchange Trades and Automated Quotations databases (TAQ) for 1993 to 2003. Closing-quote data for NASDAQ stocks come from CRSP. For ISSM and TAQ data, if the final quote of the day is beyond 10 minutes after the market's close, we exclude the quote. ${ }^{5}$ For all stocks,

\footnotetext{
${ }^{5}$ The vast majority of final quotes are recorded within a few minutes of 4:00 p.m.; however, cursory examination of the data reveals some cases in which the final quote appears up to several hours after the market closes. We use the last quote before 4:10 p.m. to avoid any issues associated with late quotes. If a Wednesday price is missing due to a holiday, we use Tuesday's closing price. Also, price data are missing for NYSE-AMEX stocks on 43 Wednesdays across 1983-1991 and for NASDAQ stocks in February 1986. In later sections when we use multiweek returns, we avoid the loss of observations surrounding these missing data by computing multiweek returns with Wednesday prices adjacent to the missing week(s), adjusting these prices for dividends and splits.
} 
we obtain dividend and split data from CRSP and account for these events in our return calculations. We exclude all stocks priced below five dollars at the end of formation week $t$ (to avoid extremely illiquid stocks).

With midpoint returns in hand, we rank all stocks in week $t$ based on that week's return. The stocks in the highest decile are labeled "winners," and the stocks in the lowest decile are labeled "losers." Winner and loser portfolios are equally weighted across all component stocks. We then form a portfolio that is long the winner portfolio and short the loser portfolio. In all reported results, negative profits reflect reversal in returns and positive profits reflect momentum. To evaluate the performance of the winner-minus-loser portfolio over holding periods longer than 1 week, we employ the calendar-time method advocated by Fama (1998) and Mitchell and Stafford (2000) and used by Jegadeesh and Titman (1993). The calendar-time method avoids overlapping returns and the accompanying strongly positive serial correlation in returns while allowing all possible formation periods to be considered.

Essentially, the calendar-time method overlaps portfolios instead of returns. For example, suppose we wish to evaluate the performance of the portfolios in event weeks $t+1$ to $t+52$. In a given calendar week $\tau$, there are 52 strategies that week-one formed in week $\tau-1$, one formed in week $\tau-2$, and so on. The profit in calendar week $\tau$ is the equally weighted average of the 52 overlapping cohort portfolios' profits in that calendar week. Rolling forward to the next week, we drop the oldest portfolio and add the newest portfolio. After computing the equally weighted profit for each calendar week of the sample period, we have a single weekly calendar-time series of profits representing the event window $t+1$ through $t+52$. Other event windows are examined similarly.

We consider several metrics for evaluating the performance of the winnerminus-loser portfolio in any given holding-period window. The strategy's raw profit for a particular holding period window is simply the mean of the calendartime series of profits. We also calculate weekly CAPM and Fama-French threefactor alphas by regressing the calendar-time series of winner-minus-loser profits on the appropriate factor premia. ${ }^{6}$

Since we detect positive serial autocorrelation in the profit series, we calculate all test statistics using the consistent variance estimator of Gallant (1987). Following Andrews (1991), the bandwidth employed by the estimator is determined assuming an AR(1) process and using Andrews' equations (6.2) and (6.4). Also following Andrews' recommendation, we examine several alternative bandwidths by adding \pm 1 and \pm 2 standard deviations to the autoregressive parameter. The number of lags used in estimating the standard errors of the portfolio's profits ranges from 0 to 13. Our findings are robust across the various bandwidths.

Two concerns surrounding the use of a calendar-time procedure are the potential heteroskedasticity in the portfolio's profit series and the potential time variation in the portfolio's factor loadings. Both of these effects might arise as the composition of the portfolio changes week by week. However, because

\footnotetext{
${ }^{6}$ We thank Kenneth French for providing daily data on the Fama-French factors and the risk-free rate via his website.
} 


\section{Table I}

\section{Profits to Weekly Extreme Portfolios (Winners minus Losers)}

Each week from 1983 to 2003, we rank stocks based on their returns over the week and form a portfolio comprised of a long position in the top decile of stocks (winners) and a short position in the bottom decile (losers). Returns are formed from the midpoints of the quoted bid and ask prices at each day's close. Stocks priced below five dollars at the end of formation week $t$ are excluded. Calendar-time alphas are estimated over various holding periods using raw returns, the CAPM, and the Fama-French three-factor model. The $t$-statistics are in parentheses and are robust to heteroskedasticity and autocorrelation. Profits are in basis points.

\begin{tabular}{lccccc}
\hline & \multicolumn{5}{c}{ Holding Period } \\
\cline { 2 - 5 } & Week & Week & Week & Weeks & Weeks \\
& 1 & 2 & 3 & $4-52$ & $1-52$ \\
\hline \multirow{2}{*}{ Raw } & -70.61 & -37.41 & 0.94 & 8.11 & 5.10 \\
& $(-8.10)$ & $(-5.67)$ & $(0.18)$ & $(4.59)$ & $(2.85)$ \\
CAPM & -66.96 & -33.30 & 3.42 & 8.51 & 5.67 \\
Fama-French & $(-7.86)$ & $(-5.24)$ & $(0.63)$ & $(5.21)$ & $(3.49)$ \\
& -68.56 & -34.27 & 0.97 & 8.56 & 5.60 \\
& $(-8.17)$ & $(-5.29)$ & $(0.18)$ & $(4.75)$ & $(3.08)$ \\
\hline
\end{tabular}

the winner-minus-loser portfolios select $20 \%$ of available stocks each month by design, these concerns are mitigated. Additionally, the standard errors in all the tests are robust to heteroskedasticity as just discussed. Nevertheless, as a robustness check of our findings, we employ a standardization procedure that can account for both heteroskedasticity in the profit series and time variation in the factor loadings. The procedure is detailed in Section V.A. Our conclusions are unaffected by the use of this procedure.

\section{Performance of Extreme Weekly Portfolios}

We begin by evaluating the performance of stocks with extreme weekly returns over a longer horizon than just a few weeks. Table I provides the mean weekly profits to the portfolio of last week's winner stocks minus last week's loser stocks over various holding periods. We see that extreme weekly returns reverse. Reversal in the first week after portfolio formation is strong, averaging around 69 basis points per week across raw and risk-adjusted metrics. Since we are using midpoint returns, bid-ask bounce is clearly not the sole source of return reversal. ${ }^{7}$ Lo and MacKinlay (1990) and Jegadeesh and Titman (1995a, 1995b) identify nonsynchronous trading, inventory management by dealers,

\footnotetext{
${ }^{7}$ Using midpoint returns of NASDAQ stocks from 1983-1990 and using a weighting scheme similar to Lehmann's (1990), Conrad, Hameed, and Niden (1994) do not find statistically significant weekly reversal in returns $(t=-1.60)$. We also find no reversal for our winner-minus-loser portfolio using only NASDAQ stocks over their time period. However, midpoint returns of NASDAQ stocks do reverse strongly after 1990 and over the full period 1983-2003. So their no-reversal finding is confined to their sample period. Also, NYSE/AMEX stocks reverse during the 1983 to 1990 period and over the full period.
} 
and investor overreaction to firm-specific news as possible sources of the reversal found in Table I. ${ }^{8}$

Consistent with all three of these hypotheses, and with the empirical evidence of prior studies, the reversal in returns diminishes quickly and is gone by week 3 . However, the profit to the portfolio of winners minus losers across $[t+4, t+$ $52]$ is positive and at least 8.11 basis points per week. This is the central finding of this study. Figure 1 plots the cumulative raw profits to the weekly portfolios across the 52 weeks following portfolio formation, estimating the profits in each event week separately. The figure shows a dramatic run-up in the cumulative profits after week 3 . In fact, the run-up is strong enough to overcome the initial reversal, with cumulative profits exceeding $3 \%$ one year after portfolio formation. Table I shows that the profits in weeks $[t+1, t+52]$ are statistically positive across all performance metrics, and are at least 5.10 basis points on average per week across 52 weeks. In short, we find that the extreme returns in the formation week continue over the next year, suggesting ex post that extreme weekly returns are actually not extreme enough. ${ }^{9}$

This new result is a turnaround for the literature on the short-run predictability of individual stock returns. For almost two decades, reversal has been the lone stylized fact of weekly returns. The potential underlying sources of reversal have therefore been extensively examined and debated. We find, however, that reversals are accompanied by and eventually dominated by a momentum effect. Our finding complements the evidence of momentum in firm-specific events and headline news as well as in 3-to 12-month returns, as noted in the introduction. We find this comforting, as short-run reversal in weekly returns seems inconsistent with these other findings. ${ }^{10}$

To provide further evidence that momentum is a salient feature of weekly returns, we examine the profits of the less-extreme winner-minus-loser portfolios. Table II shows that reversal of raw returns is evident in week $t+1$ only in the extreme (decile 10-decile 1) portfolio. All other portfolios generate significant momentum profits in week 1 . (These results are similar when CAPM or Fama-French alphas are used.) We should note that for the less-extreme portfolios, the momentum in week $t+1$ returns is attributable to NASDAQ

\footnotetext{
${ }^{8}$ Madhavan and Smidt (1993), Hasbrouck and Sofianos (1993), Hansch, Naik, and Viswanathan (1998), and Hendershott and Seasholes (2006) find that prices quoted by dealers are inversely related to their inventory and that inventory is mean reverting. These findings indicate that dealers actively manage their inventories.

${ }^{9}$ Note that the magnitudes of the weekly profits in Table I might not be realizable after trading costs are imposed. Regardless, this should not discredit the importance of our finding of momentum in weekly returns. Whether profits are realizable or not is an interesting (and difficult) issue to consider, but it does not affect the reality that momentum exists in weekly returns.

${ }^{10}$ We also decompose the formation-week returns into firm-specific and factor-based price movements using the CAPM and the Fama-French three-factor models, respectively, where the factor loadings of each stock are estimated over weeks $[t-52, t-1]$, requiring at least 26 nonmissing weeks. Longing the top decile and shorting the bottom decile of stocks according to the firm-specific and factor-based price changes reveals that both the week-1 reversal and the longer-run momentum are solely due to the firm-specific portion of return. Grundy and Martin (2001) reach the same conclusion for 6 -month momentum.
} 
Table II

Profits to Less-Extreme Portfolios (Winners minus Losers)

Each week from 1983 to 2003, we sort stocks into deciles based on their returns over the week. Returns are formed from the midpoints of the quoted bid and ask prices at each day's close. Stocks priced below five dollars at the end of formation week $t$ are excluded. We form a $(10-1)$ portfolio comprised of a long position in the top decile of stocks (winners) and a short position in the bottom decile (losers), a (9-2) portfolio comprised of a long position in the second-highest decile and a short position in the second-lowest decile, and a $(8-3)$, a (7 - 4), and a $(6-5)$ portfolio correspondingly. The raw profits of these various winner-minus-loser portfolios are reported over different holding periods. The $t$-statistics are in parentheses and are robust to heteroskedasticity and autocorrelation. CAPM and Fama-French risk-adjusted profits produce similar findings. Profits are in basis points.

\begin{tabular}{lccc}
\hline & & Holding Period & \\
\cline { 2 - 4 } & Week & Week & Weeks \\
Winner-Loser & 1 & 2 & $1-52$ \\
\hline $10-1$ & -70.61 & -37.41 & 5.10 \\
& $(-8.10)$ & $(-5.67)$ & $(2.85)$ \\
$9-2$ & 24.17 & -14.70 & 3.36 \\
& $(5.19)$ & $(-3.30)$ & $(3.06)$ \\
$8-3$ & 34.20 & -3.44 & 2.19 \\
& $(10.81)$ & $(-1.10)$ & $(3.18)$ \\
$7-4$ & 24.24 & -4.55 & 0.75 \\
& $(9.53)$ & $(-1.60)$ & $(1.73)$ \\
& 8.18 & 0.64 & -0.24 \\
& $(4.44)$ & $(0.34)$ & $(-0.79)$ \\
\hline
\end{tabular}

stocks. ${ }^{11}$ However, additional untabulated results find that when using just NYSE stocks, only portfolios $(10-1)$ and $(9-2)$ reverse; the less-extreme portfolios do not. In short, Table II shows that, after eliminating bid-ask bounce by using midpoint returns, reversal in weekly returns does not always occur, whereas momentum is pervasive. The profits in the less-extreme portfolios in Table II are statistically positive across weeks 1-52 (except in portfolio (6-5), where the formation-week return spread is only roughly 80 basis points). Thus, momentum, not reversal, is the strong and consistent effect in weekly returns. ${ }^{12}$

We should note for completeness that we also examine the winner and loser subportfolios separately to ascertain if one side of the portfolio or the other accounts for a large portion of the momentum profits. There is some evidence that losers contribute more to the profits of the winner-minus-loser portfolio over $[t+1, t+52]$, similar to Hong, Lim, and Stein's (2000) and Chan's (2003) momentum results, but this finding is sensitive across our robustness checks. Some specifications find that winners contribute more. Further, when the losers are found to provide the bulk of the profits, their performance is often not

\footnotetext{
${ }^{11}$ Ball, Kothari, and Wasley (1995) examine bid-to-bid returns on NASDAQ stocks from 19831990 and also detect momentum in the less-extreme portfolios. We pursue the notion of an exchange effect in short-run return reversal, but the additional test indicates that the exchange effect is subsumed by the size and return-volatility effects noted in Section IV.C.

12 These findings are unchanged if we skip a day between the formation and testing periods.
} 
statistically different from zero. Therefore, we focus our analyses in the rest of the paper on the return spreads between winners and losers, as prior studies do, since this is the more powerful and reliable test. The spread between winners and losers is robustly anomalous.

\section{Are These Findings New?}

Before we discuss the implications of momentum in 1-week returns, we address potential concerns that our results are manifestations of Jegadeesh and Titman's (1993) finding of momentum in longer-horizon returns. That is, we test whether the momentum in Table I really is due to returns in week $t$ or to returns over other horizons. To do so, we first examine if the explanatory power of $r_{t}$ for future returns remains after controlling for returns over the prior 13 or 26 weeks. Second, we examine if the momentum in Table I is partly due to returns after week $t$. Specifically, we examine if momentum in the latter part of the 1-year holding period is due to returns over $[t+1, t+13]$ or $[t+1, t+$ $26]$. The potential concern addressed in this second test is that the persistent run-up of profits in the first few months of the holding period might trigger a further run-up, or in other words, momentum profits over weeks $[t+1, t+52]$ might not be due to $r_{t}$ per se but to momentum arising after week $t$.

Both portfolio and regression evidence indicate that momentum following week $t$ is due to returns in week $t$ and not to pre- or post-formation returns. We also use the regression tests to examine other control variables, such as book-to-market equity, size, and other stock characteristics. In short, we find that momentum exists in 1 -week returns.

\section{A. Portfolio Evidence}

We control for pre- and post-formation returns using two-way sorting procedures. First, each week $t$ we sort stocks into five portfolios based on the prior 26-week return, $r_{[t-26, t-1]}$. We then sort each of these quintile portfolios into five portfolios based on $r_{t}$. The 1-week winner-minus-loser portfolios are identified within each prior-26-week return quintile, and the performances of the five winner-minus-loser portfolios over various holding periods are examined.

The results of this test are provided in Panel A of Table III. Momentum in 1 -week returns remains evident in each of the 26 -week quintiles except the one with the lowest returns. The last column labeled "All" provides the mean profit across the five quintiles by equally weighting the five winner portfolios and the five loser portfolios each week. These results indicate that controlling for prior 26-week returns has little effect on momentum in 1-week returns.

Panel B of Table III examines 1-week momentum controlling for returns over the post-formation period $[t+1, t+26]$. The two-way sorting procedure is analogous to the one just discussed, and the findings are similar. In sum, the results in Table III indicate that profits over $[t+1, t+52]$ from a strategy of buying winners in week $t$ and selling losers are attributable to returns in week 


\section{Table III \\ Profits to Weekly Extreme Portfolios Controlling for 26-Week Momentum (Winners minus Losers)}

Each week from 1983 to 2003, we rank stocks into quintiles based on 26-week returns. Within each 26 -week return quintile, we rank stocks into further quintiles based on 1-week returns and form portfolios comprised of long positions in the top 1-week quintile of stocks (winners) and short positions in the bottom quintile (losers). Panel A first sorts on returns over weeks $[t-26, t-1]$ and then sorts on returns over week $t$; portfolios are examined over $[t+1, t+52]$. Panel B first sorts on returns over weeks $[t+1, t+26]$ and then sorts returns over week $t$; portfolios are examined over $[t+27, t+52]$. In both panels, the column labeled "All" represents a portfolio that is weighted equally across the 26 -week-return quintiles. Returns are formed from the midpoints of the quoted bid and ask prices at each day's close. Stocks priced below five dollars at the end of formation week $t$ are excluded. Calendar-time alphas are estimated over various holding periods using raw returns. The $t$-statistics are in parentheses and are robust to heteroskedasticity and autocorrelation. CAPM and Fama-French risk-adjusted profits produce similar findings. Profits are in basis points.

\begin{tabular}{lccccc}
\hline Low & 2 & 3 & 4 & High & All \\
\hline \multicolumn{5}{c}{ Panel A: Sorting First on $r_{[t-26, t-1]}$ and Evaluating over Weeks 1-52 } \\
\hline 1.47 & 3.65 & 3.78 & 4.53 & 5.36 & 3.60 \\
$(0.71)$ & $(2.69)$ & $(3.11)$ & $(3.64)$ & $(3.66)$ & $(2.81)$ \\
\hline \multicolumn{5}{c}{ Panel B: Sorting First on $r_{[t+1, t+26]}$ and Evaluating over Weeks 27-52 } \\
\hline 6.30 & 6.25 & 6.45 & 6.53 & 8.04 & 6.69 \\
\hline 4.57$)$ & $(6.09)$ & $(6.25)$ & $(6.06)$ & $(6.39)$ & $(7.17)$ \\
\hline
\end{tabular}

$t$ and not to returns over other horizons. The use of CAPM and Fama-French alphas to evaluate performance does not alter this conclusion.

\section{B. Regression Evidence}

We continue examining the robustness of 1-week momentum using weekly cross-sectional regressions. The regression setting allows us to easily control for multiple characteristics (as opposed to using three-way or higher-order sortings in the portfolio tests). Each week $t$, we regress the cross-section of return over $[t+1, t+52]$ on the return in week $t$, the return over $[t-1, t-26]$, size, and the book-to-market-equity ratio $\left(\frac{B}{M}\right)$. We measure size as the market value of the stock in the last available week of the prior June, and we measure $\frac{B}{M}$ as the book value of equity at fiscal year-end (Compustat item 60) divided by the market value of equity in the last available week of the prior December. Both size and $\frac{B}{M}$ are sampled in week $t$, along with the 1-week return, and natural logarithms of both size and $\frac{B}{M}$ are used in the regressions.

Once the weekly regressions are estimated, the respective time series of each coefficient is used to separately test the hypothesis that its mean is zero. The overlapping of the left-hand variable and some of the right-hand variables induces positive serial correlation in the time series of coefficient estimates. This needs to be accounted for in the test statistics. We rely on the variance estimator 


\section{Table IV}

\section{Weekly Cross-sectional Regressions}

Each week from 1984 to 2002 , we regress the cross-section of future holding-period return on the 1-week return, 26 -week return, and 13-week return, sampled at various horizons. The mean of the weekly time series of each coefficient is reported below and is tested to be zero. The $t$-statistics are in parentheses and are robust to heteroskedasticity and autocorrelation. The mean coefficients on the 1 -week return are given in column 1 . The mean coefficients of the 26 -week and 13 -week returns, sampled at various points, are given in columns 2 and 3, respectively. The log of the bookto-market ratio (column 4) and size (column 5) are included as controls and are updated the first week in January and the first week in July respectively, and are sampled at week $t$. Returns are formed from the quoted bid and ask prices at each day's close. Stocks priced below five dollars at the end of the week from which the 1-week return is sampled are excluded. Reported coefficient estimates are multiplied by 100 .

\begin{tabular}{lccccc}
\hline & \multicolumn{1}{c}{1} & 2 & 3 & 4 & 5 \\
\cline { 2 - 5 } Future Return & \multicolumn{5}{c}{ Explanatory Variables } \\
\hline A. $r_{[t+1, t+52]}$ & $r_{t}$ & $r_{[t-26, t-1]}$ & $\ln \left(\frac{B}{M}\right)$ & $\ln ($ size $)$ \\
\cline { 2 - 5 } & 9.20 & 12.56 & 8.88 & 0.74 \\
& $(4.14)$ & $(4.55)$ & & $(6.24)$ & $(1.20)$ \\
B. $r_{[t+14, t+52]}$ & $r_{t}$ & $r_{[t-26, t-1]}$ & $r_{[t+1, t+13]}$ & $\ln \left(\frac{B}{M}\right)$ & $\ln ($ size $)$ \\
\cline { 2 - 5 } & 12.19 & 7.26 & 11.01 & 5.12 & 0.32 \\
C. $r_{[t+27, t+52]}$ & $(6.85)$ & $(3.83)$ & $(4.19)$ & $(4.43)$ & $(0.70)$ \\
& $r_{t}$ & $r_{[t+1, t+26]}$ & $r_{[t-13, t-1]}$ & $\ln \left(\frac{B}{M}\right)$ & $\ln ($ size $)$ \\
\cline { 2 - 5 } & 7.05 & 5.22 & 6.07 & 2.49 & 0.13 \\
& $(5.34)$ & $(3.06)$ & $(3.78)$ & $(3.30)$ & $(0.41)$ \\
\hline
\end{tabular}

of Gallant (1987), which is robust to heteroskedasticity and to serial correlation. Once again, we follow the advice of Andrews (1991) and model each time series as an AR(1) process to determine the bandwidth parameter of the kernel estimator (using equations (6.2) and (6.4) of Andrews). We then examine robustness across alternative bandwidths, again following Andrews's recommendation, by changing the autoregressive parameter by \pm 1 and \pm 2 standard deviations. The number of lags used in testing the coefficient on $r_{t}$ ranges from 6 to 10 across the various bandwidths and the various models considered. The findings to be discussed next are robust across bandwidths and across models. ${ }^{13}$

The results of the regression-based tests are provided in Table IV. Panel A confirms the portfolio results of Table III. The explanatory power of $r_{t}$ for $r_{[t+1, t+52]}$ remains strong after controlling for $r_{[t-26, t-1]}$; the $t$-statistic for $r_{t}$ is

${ }^{13}$ The other right-hand variables, which are the longer-horizon returns, size, and $\frac{B}{M}$, overlap sizably in the weekly regressions so their AR(1) parameters notably increase. As such, the number of lags employed to test these respective coefficients increases. For example, the number of lags used to test the coefficient on $r_{[t-1, t-26]}$ ranges from 65 to 201 . With a time series of roughly 950 observations, readers might be justifiably concerned about the reliability of the estimates of the standard errors when the number of lags is so large. However, the focus of this study is on the explanatory power of $r_{t}$, not the control variables. Since all coefficient estimates are consistent, we can be confident in the test statistics for $r_{t}$. 
4.14. In addition, controlling also for $\frac{B}{M}$ and size does not affect the finding of momentum in 1-week returns. Although the results are not tabulated, we also confirm that none of the findings in Table IV are affected by the inclusion of a stock's return volatility, analyst coverage, and institutional ownership as additional control variables (defined in Section IV.C).

Panel B of Table IV adds $r_{[t+1, t+13]}$ as an additional control. The explanatory power of $r_{t}$ for future returns, in this case for $r_{[t+14, t+52]}$, continues to hold. Panel $\mathrm{C}$ switches the horizons of the pre-formation and post-formation controls. That is, in Panel $\mathrm{C}$ we explain $r_{[t+27, t+52]}$ using $r_{t}$, lagged 13-week returns, and leading 26 -week returns. Again, the findings in Table I are not driven by longer-horizon effects. In short, long-lasting momentum exists in 1-week returns.

The regression setting also allows us to directly compare the information about future returns found in 1-week returns to that found in longer-horizon returns. We see in Table IV that the coefficients on the different return horizons are of the same magnitude, indicating that the information contained in all return horizons is roughly comparable. Importantly then, the ability of past returns to predict future returns (i.e., momentum) is more related to the size of the past return than to its horizon. Of course, each horizon does have distinct explanatory power for future returns, as shown in Tables III and IV, because each horizon embodies a separate piece of information.

\section{New Testing Ground for Momentum Theories}

Perhaps the most important contribution of the finding of momentum in 1-week returns is the recognition that momentum is not exclusive to returns from 3 to 12 months, as the literature currently suggests. Our findings provide financial economists a simpler, clearer picture of the anomaly landscape: Return momentum is the dominant feature of returns of all horizons up to 12 months. Given this observation, potential explanations of momentum should be easier to develop. ${ }^{14}$

An outgrowth of the finding of momentum in weekly returns is that economists now have a new testing ground for momentum theories. Weekly returns can potentially reveal new information about the underlying process of price formation that produces momentum. Moreover, weekly returns can allow researchers to link returns to specific news events, an opportunity that does not exist at the 6- or 12-month horizons commonly used in momentum studies. Therefore, theories investigating how specific types of news might drive momentum should be better tested using momentum in 1-week returns than momentum in longer-horizon returns.

In the next subsections, using weekly returns, we revisit Chan's (2003) investigation of the relation between momentum and public news and Zhang's (2006) investigation of the relation between momentum and information un-

\footnotetext{
${ }^{14}$ Interestingly, the most prominent theories of return momentum developed by Daniel et al. (1998), Hong and Stein (1999), and Barberis, Shleifer, and Vishny (1998) all ignore the short-run reversal. Our findings justify this omission.
} 
certainty. In particular, we consider whether the theories of momentum that they examine are potential contributors to the momentum in 1-week returns.

\section{A. Explicit versus Implicit News}

As Chan (2003) and many others note, we can think of price movements as reflecting private or intangible news, not just publicly available news. Several current and prominent behavioral theories of stock return anomalies predict that the market overreacts to price movements not associated with public firmspecific news. Daniel et al. (1998) assume that investors' overconfidence in their private information yields an overreaction to private information and an underreaction to public information. Hong and Stein (1999) assume that there are two types of investors, one type that observes only public fundamental news about firms and a second type that observes only price movements. With the additional assumption that information about fundamentals diffuses gradually across the marketplace, Hong and Stein predict that public news will be underreacted to and that price movements will be overreacted to. Daniel and Titman (2006) suggest that investors overreact to intangible news, which they specify as price movements unrelated to accounting measures of performance. The central assertion of these theories is that the market overreacts to returns that are unassociated with public news. We label such news "implicit" since no explicit news is released.

Chan (2003) separates monthly stock returns into price movements that are and are not associated with media headline news, that is, into explicit and implicit news respectively. He finds that implicit news generates reversal in subsequent returns and explicit news generates momentum. Chan concludes that indeed the market might be overreacting to implicit news and underreacting to explicit news.

Using Chan's (2003) data on headline news, we reexamine the performances of implicit-news and explicit-news portfolios. We link headline news to 1-week returns, instead of 1-month returns, to provide a cleaner identification of the type of news underlying price movements. Chan's headline data are collected from the Dow Jones Interactive Publications Library from 1980 to 2000. Each day he identifies if a given stock is mentioned in a headline or lead paragraph from a newspaper or newswire article. To render the data collection feasible, he selects a random subset of roughly $25 \%$ of CRSP stocks, varying from 766 in January 1980 to over 1,500 in December $2000 .^{15}$

We rank the superset of all available stocks using CRSP and ISSM/TAQ (as in Table I) into deciles each week from 1983 to 2000 based on midpoint returns from the prior week (the midpoint data begin in 1983). Using the breakpoints from the superset allows us to compare profits across implicit and explicit stocks

\footnotetext{
${ }^{15}$ See Chan's (2003) description of the data for more details. We collect announcement data on earnings, seasoned equity offerings, stock splits, dividend initiations, and share repurchases and compare these with Chan's headline-news data. This exercise suggests that his data are comprehensive.
} 


\section{Table V \\ Profits to Explicit-News and Implicit-News Portfolios (Winners minus Losers)}

Each week from 1983 to 2000 , we rank stocks based on their returns over the week. Within the highest decile of stocks (winners) and the lowest decile (losers), we then identify the stocks in Chan's (2003) random sample and separate these stocks into those with headline news in the week (explicit news) and those without headline news (implicit news). We form an implicit-news portfolio by taking a long position in the winner stocks with implicit news over the week and a short position in loser stocks with implicit news. An explicit-news portfolio is formed analogously. Calendar-time raw profits are estimated over various holding periods. Panel A reports the profits to the implicitnews portfolio, and Panel B reports the profits to the explicit-news portfolio. The $t$-statistics are in parentheses and are robust to heteroskedasticity and autocorrelation. Returns are formed from the midpoints of the quoted bid and ask prices at each day's close. Stocks priced below five dollars at the end of formation week $t$ are excluded. CAPM and Fama-French risk-adjusted profits produce similar findings. Profits are in basis points.

\begin{tabular}{|c|c|c|c|c|}
\hline \multicolumn{5}{|c|}{ Holding Period } \\
\hline Week & Week & Week & Weeks & Weeks \\
\hline 1 & 2 & 3 & $4-52$ & $1-52$ \\
\hline \multicolumn{5}{|c|}{ Panel A: Implicit News (no headline news) } \\
\hline $\begin{array}{l}-81.11 \\
(-6.93)\end{array}$ & $\begin{array}{r}-45.76 \\
(5.32)\end{array}$ & $\begin{array}{c}-6.13 \\
(-0.81)\end{array}$ & $\begin{array}{c}8.79 \\
(5.41)\end{array}$ & $\begin{array}{c}5.21 \\
(3.13)\end{array}$ \\
\hline \multicolumn{5}{|c|}{ Panel B: Explicit News (headline news) } \\
\hline $\begin{array}{l}-60.33 \\
(-4.29)\end{array}$ & $\begin{array}{c}-8.96 \\
(-0.88)\end{array}$ & $\begin{array}{c}20.03 \\
(2.53)\end{array}$ & $\begin{array}{l}12.49 \\
(6.04)\end{array}$ & $\begin{array}{c}9.85 \\
(4.25)\end{array}$ \\
\hline \multicolumn{5}{|c|}{ Panel C: $t$-test of (Explicit-Implicit $)=0$} \\
\hline (2.19) & $(4.14)$ & (3.06) & $(2.06)$ & $(2.41)$ \\
\hline
\end{tabular}

as the formation-period returns are similar. Stocks in the extreme deciles that are in Chan's (2003) data are identified and separated into implicit-news and explicit-news stocks depending on whether a given stock has at least one headline news release during the formation week. We impose a 10-stock requirement on each winner and loser portfolio in week $t$ to mitigate potential consequences of heteroskedasticity and of variations in factor loadings that may result from the portfolio's composition changing from one calendar week to the next.

Table $\mathrm{V}$ provides the raw profits to implicit-news and explicit-news portfolios comprised of implicit-news winners minus implicit-news losers and explicitnews winners minus explicit-news losers, respectively. For brevity, we do not tabulate the CAPM and Fama-French alphas since these metrics produce similar results. In Panel A, we find, as Chan (2003) does, that implicit news reverses immediately after portfolio formation. However, information from the longer evaluation windows suggests that implicit news in week $t$ is not categorically overreacted to. As before, there is a robust stream of momentum profits following the brief reversal that is strong enough to offset the initial reversal. The last column in Table V shows that the profit to the implicit-news portfolio is 
statistically positive in the 52 weeks following portfolio formation. So, just as in the general case of Table I, extreme price movements not associated with headline news are found ex post to be not extreme enough.

Moreover, implicit-news stocks and explicit-news stocks display the same general behaviors, namely, short-run reversal and longer-run momentum. Panel B provides the profits to the explicit-news portfolio. Panel C provides the $t$-statistics comparing the mean profits of the explicit-news portfolio to those of the implicit-news portfolio. Interestingly, the profits to explicit news are statistically greater than the profits to implicit news over every holding period examined in Table V. Given that the formation-period returns are similar, we have evidence that the market does react differently to implicit versus explicit news. However, the difference between implicit and explicit news is not as the aforementioned theories predict. Since both groups display the same qualitative pattern of short-run reversal and longer-run (stronger) momentum, we are unable to characterize one reaction as overreaction and the other as underreaction. The only difference is in the magnitudes of the profits, not in the patterns of the profits. Why this difference in magnitudes exists is an interesting topic for future studies to pursue.

It is worth noting that earnings announcements do not drive the stronger momentum in explicit news. Removing stocks that announce earnings in week $t$ from the explicit-news portfolio diminishes momentum profits over weeks $[t+$ $1, t+52]$, but explicit-news profits are still significantly greater than implicitnews profits. ${ }^{16}$

In sum, our findings impede concluding that the market categorically overreacts to implicit news. Moreover, firm-specific news of all sorts, explicit and implicit, appears to robustly generate momentum in returns.

\section{B. Uncertainty and Momentum}

As just noted, explicit news displays greater return momentum than implicit news. One possible explanation is that explicit news is more precise than implicit news (in the sense of a less noisy signal), and greater precision induces greater momentum. ${ }^{17}$ However, in his examination of the relation between momentum and several measures of the uncertainty (or ambiguity) of the valuation impact of a given piece of firm-specific news, Zhang (2006) finds the seemingly opposite result that momentum increases with uncertainty. Zhang's hypothesis is that if psychological biases play a role in return momentum, then momentum should increase as uncertainty increases. This prediction follows from evidence that uncertainty intensifies psychological biases. ${ }^{18}$

\footnotetext{
${ }^{16}$ Earnings announcements are from I/B/E/S.

${ }^{17}$ Readers may find it difficult to envision how greater precision, that is, less uncertainty, might lead to greater momentum. Veronesi (2000) and Johnson (2004) identify mechanisms that can rationally produce higher expected returns for stocks with greater precision.

${ }^{18}$ See Hirshleifer's (2001) review for a detailed discussion.
} 
Zhang (2006) studies the relation between momentum in 11-month returns and the general uncertainty regarding a stock's valuation using such measures as size, analyst coverage, return volatility, and the dispersion of analysts' earnings forecasts. We extend his analyses to momentum in 1-week returns. By using such a short horizon, we can link momentum to specific news releases. Moreover, for earnings announcements in particular, we have a measure of the ex ante uncertainty of the given news, namely, the dispersion of analysts' earnings forecasts. Therefore, we have a seemingly more reliable and direct test of the relation between return momentum and the uncertainty of news. ${ }^{19}$

We define dispersion of the earnings forecasts to be the standard deviation of forecasts scaled by the stock's price at the end of week $t-1$. We exclude observations with fewer than four forecasts to increase our confidence in the measure of dispersion. Similar results obtain when stocks with less than four earnings forecasts are included or when the standard deviation is scaled by the absolute value of the mean earnings forecast. The forecast data are unadjusted for splits and are provided by I/B/E/S. Diether, Malloy, and Scherbina (2002) and Payne and Thomas (2003) note that using standard deviations of forecasts that are historically adjusted for splits can falsely classify high-dispersion stocks as low-dispersion stocks. Earnings announcement and forecast data begin May 1984.

Each week $t$, stocks are sorted into deciles based on returns in week $t$ (as in Table I). Winner (top-decile) stocks that announce earnings in week $t$ are sorted based on the dispersion of earnings forecasts. Stocks with dispersion above the median value for that winner portfolio are classified as the high-dispersion winner stocks; stocks with below-median dispersion are classified as the lowdispersion winner stocks. The low-dispersion and high-dispersion portfolios of loser (bottom-decile) stocks are formed analogously.

One last detail to note is that we alter the weighting scheme within the calendar-time portfolios when examining holding periods greater than 1 week. In other tests, we equally weight across all cohort portfolios held that week. For example, for the performance analysis across weeks $[t+1, t+52]$, we equally weight the returns of the 52 portfolios in calendar week $\tau$ to estimate the portfolio's return. Since we are faced in some calendar weeks of these dispersion tests with very few stocks being held in specific cohort portfolios, we equally weight across all stocks held that week, instead of across cohort portfolios. Finally, we require at least 10 stocks in the winner and loser portfolios each calendar week for that week to be included in the analyses. In testing over $[t+1, t+52]$ for whether momentum differs across forecast dispersion, each week we average roughly 300 stocks on the portfolio's long side and 300 stocks on the short side and lose only 46 out of 1,022 weeks (and these dispersion portfolios have on average the least number of stocks per week among the 52-week portfolios examined in this study).

\footnotetext{
${ }^{19}$ The measure of uncertainty remains indirect in our test as well because we are measuring the uncertainty of future earnings instead of the uncertainty of the valuation impact of the earnings.
} 


\section{Table VI}

\section{Profits to Weekly Extreme Portfolios across High and Low Dispersion in Earnings Forecasts (Winners minus Losers)}

Each week from May 1984 to 2003, we rank stocks based on their returns over the week. Within the highest decile of stocks (winners) and the lowest decile (losers), we retain the stocks with (1) a quarterly earnings announcement occurring in the week and (2) earnings forecasts provided by at least four analysts. We separate the remaining winner stocks into those with high (above-median) and low (below-median) dispersion in earnings forecasts. We form a high-dispersion portfolio by taking a long position in winner stocks with high forecast dispersion and a short position in loser stocks with high forecast dispersion. A low-dispersion portfolio is formed analogously. Raw profits are estimated over various holding periods. Panel A reports the profits to the high-dispersion portfolio, and Panel B reports the profits to the low-dispersion portfolio. The $t$-statistics are in parentheses and are robust to heteroskedasticity and autocorrelation. Returns are formed from the midpoints of the quoted bid and ask prices at each day's close. Stocks priced below five dollars at the end of formation week $t$ are excluded. CAPM and Fama-French risk-adjusted profits produce similar findings. Profits are in basis points.

\begin{tabular}{|c|c|c|c|c|}
\hline \multicolumn{5}{|c|}{ Holding Period } \\
\hline Week & Week & Week & Weeks & Weeks \\
\hline 1 & 2 & 3 & $4-52$ & $1-52$ \\
\hline \multicolumn{5}{|c|}{$\begin{array}{l}\text { Panel A: High Dispersion in Earnings Forecasts } \\
\text { (and earnings released in week } t \text { ) }\end{array}$} \\
\hline $\begin{array}{l}23.76 \\
(0.99)\end{array}$ & $\begin{array}{l}13.81 \\
(0.59)\end{array}$ & $\begin{array}{l}29.71 \\
(1.46)\end{array}$ & $\begin{array}{l}10.15 \\
(3.05)\end{array}$ & $\begin{array}{l}10.50 \\
(3.25)\end{array}$ \\
\hline \multicolumn{5}{|c|}{$\begin{array}{l}\text { Panel B: Low Dispersion in Earnings Forecasts } \\
\text { (and earnings released in week } t \text { ) }\end{array}$} \\
\hline $\begin{array}{l}0.67 \\
(0.03)\end{array}$ & $\begin{array}{l}17.12 \\
(0.79)\end{array}$ & $\begin{array}{l}-5.51 \\
(-0.28)\end{array}$ & $\begin{array}{l}13.10 \\
(4.02)\end{array}$ & $\begin{array}{l}12.01 \\
(3.85)\end{array}$ \\
\hline \multicolumn{5}{|c|}{ Panel C: $t$-test of (High-Low $)=0$} \\
\hline$(0.67)$ & $(-0.15)$ & (1.38) & $(-0.94)$ & $(-0.51)$ \\
\hline
\end{tabular}

Table VI provides the raw profits to the high-dispersion and low-dispersion portfolios of winner-minus-loser stocks announcing earnings. In contrast to Zhang's (2006) findings, we see no evidence that the profits to the highdispersion portfolios are different from the profits to the low-dispersion portfolios over any of the horizons considered. Panel $\mathrm{C}$ of Table VI gives the $t$-statistics for testing that the profits across high-dispersion and low-dispersion portfolios are equal. The null hypothesis of equality cannot be rejected. In short, we find no relation between uncertainty and momentum in 1-week return. The CAPM and Fama-French alphas depict the same finding and are not tabulated.

In the next section, we consider how other characteristics relate to momentum. Some of these results echo Zhang's (2006) findings; some do not. Our message here is that the relation between uncertainty and momentum that Zhang detects using 11-month returns does not transfer to momentum at the 1-week horizon. 


\section{Relations between Momentum and Stock Characteristics}

In this section, we examine how momentum in 1-week returns varies across stock size, return volatility, analyst coverage, and institutional ownership. These measures are typically used to probe how anomalies are affected by variation in information environments, trading costs, and investor sophistication. Of course, the interpretations of these characteristics are not mutually exclusive. Though we focus more on the momentum phenomenon, for completeness we continue to provide the profits for the winner-minus-loser portfolios over weeks 1,2 , and 3 .

We begin with stock size. After sorting all stocks into deciles each week based on returns over week $t$ (as in Table I), we further sort the stocks in the highest and lowest decile portfolios based on their market values at the end of the prior June. We use the median size of NYSE stocks from the prior June to classify large and small stocks. Stocks below the median value of size are grouped to form the small-stock portfolio; stocks above the median value of size are grouped to form the large-stock portfolio.

Panel A of Table VII provides the raw profits to small-stock and large-stock winner-minus-loser portfolios. (All findings in Table VII are similar when using CAPM and Fama-French alphas.) Extreme-return portfolios comprised of small stocks only and of large stocks only behave similarly, both displaying shortrun reversal and both displaying longer-run momentum after week 4 . The $t$ statistics testing whether the profits across the small-stock and large-stock portfolios are different over weeks $[t+1, t+52]$ exceed 2.90 across the three performance metrics (raw, CAPM, and Fama-French), and are not tabulated. Hence, small stocks display greater longer-run momentum, consistent with the results of Hong et al. (2000) and others. This is possibly attributable to smaller stocks being more difficult to value, having less sophisticated traders, being more costly to arbitrage, and/or having a poorer information environment.

For the large-stock extreme portfolio, although the mean profit of 1.26 basis points per week is not statistically significant over the $[t+1, t+52]$ period, it is statistically positive over the $[t+4, t+52]$ period. Hence, 1 -week returns of large stocks do generate a momentum in returns.

We turn our attention now to the other characteristics. Given that return momentum is stronger in small stocks, we control for size going forward to ensure that we are not confounding the effects of the other characteristics with the size effect. For each of the remaining characteristics examined in Table VII, we employ the following sorting procedures to create size-neutral portfolios. After identifying the winner stocks in week $t$, we sort the winners based on size measured at the end of the prior June. Using the $70^{\text {th }}$ and $30^{\text {th }}$ size percentiles for NYSE stocks from the prior June, the winner portfolio is subdivided into three portfolios: large, medium, and small. Each of these three size-based winner portfolios is further sorted into two subportfolios based on the characteristic we are examining, for example, institutional ownership (IO). Stocks with IO below the median level for stocks in their respective winner/size portfolios are grouped together as low-IO stocks; stocks with IO above the median level for 


\section{Table VII}

\section{Profits to Weekly Extreme Portfolios across Stock Characteristics (Winners minus Losers)}

Each week from 1983 to 2003, we rank stocks based on their returns over the week. We further divide the top-decile (winner) stocks and the bottom-decile loser stocks based on the various characteristics below. For Panel A, we divide winners into those with market values above the median NYSE value and those below the median NYSE value. Market values are always sampled at the end of the prior June. Losers are divided similarly. We form the small-stock portfolio by taking a long position in above-median winners and a short position in below-median losers. The large-stock portfolio is formed analogously using above-median stocks. For Panel B, we divide winners and losers each week into two groups based on institutional ownership (IO) as of the prior quarter, sorting first on size to create size-neutral IO portfolios as follows. After sorting on $r_{t}$, winners are further sorted into three size groups based on the $30^{\text {th }}$ and $70^{\text {th }}$ NYSE percentiles. We form a high-IO portfolio by taking a long position in the winners with above-median IO for their respective winner-size groups and a short position in the losers with above-median IO for their respective winner-size groups. A low-IO portfolio is formed analogously. For Panels C and D, we form size-neutral portfolios as just described. Panel C forms portfolios of stocks with high (above-median) and low (below-median) weekly return volatility measured over $[t-52, t-1]$. Panel $\mathrm{D}$ forms portfolios of stocks with high (above-median) analyst coverage and low (below-median) analyst coverage, where coverage is defined as the number of analysts providing forecasts of future annual earnings and is sampled at the end of the prior month. Stocks with no coverage are excluded. Calendar-time alphas for the portfolios are estimated over various holding periods using raw returns. The $t$-statistics are in parentheses and are robust to heteroskedasticity and autocorrelation. Returns are formed from the midpoints of the quoted bid and ask prices at each day's close. Stocks priced below five dollars at the end of formation week $t$ are excluded. CAPM and Fama-French risk-adjusted profits produce similar findings. Profits are in basis points.

\begin{tabular}{|c|c|c|c|c|c|}
\hline & \multicolumn{5}{|c|}{ Holding Period } \\
\hline & $\begin{array}{c}\text { Week } \\
1\end{array}$ & $\begin{array}{c}\text { Week } \\
2\end{array}$ & $\begin{array}{c}\text { Week } \\
3\end{array}$ & $\begin{array}{c}\text { Weeks } \\
4-52\end{array}$ & $\begin{array}{c}\text { Weeks } \\
1-52\end{array}$ \\
\hline \multicolumn{6}{|c|}{ Panel A: Size } \\
\hline Small & $\begin{array}{c}-74.48 \\
(-8.13)\end{array}$ & $\begin{array}{c}-39.57 \\
(-8.22)\end{array}$ & $\begin{array}{c}0.55 \\
(0.11)\end{array}$ & $\begin{array}{c}8.80 \\
(5.38)\end{array}$ & $\begin{array}{c}5.45 \\
(3.26)\end{array}$ \\
\hline Large & $\begin{array}{r}-115.78 \\
(-8.22)\end{array}$ & $\begin{array}{c}-8.00 \\
(-0.77)\end{array}$ & $\begin{array}{l}18.33 \\
(1.88)\end{array}$ & $\begin{array}{c}4.56 \\
(2.60)\end{array}$ & $\begin{array}{c}1.26 \\
(0.57)\end{array}$ \\
\hline \multicolumn{6}{|c|}{ Panel B: Institutional Ownership } \\
\hline High & $\begin{array}{c}-86.34 \\
(-9.40)\end{array}$ & $\begin{array}{c}-40.81 \\
(-5.77)\end{array}$ & $\begin{array}{c}-1.17 \\
(-0.19)\end{array}$ & $\begin{array}{c}6.85 \\
(3.89)\end{array}$ & $\begin{array}{c}3.27 \\
(1.79)\end{array}$ \\
\hline Low & $\begin{array}{c}-67.94 \\
(-7.19)\end{array}$ & $\begin{array}{c}-30.88 \\
(-4.35)\end{array}$ & $\begin{array}{c}-2.69 \\
(-0.44)\end{array}$ & $\begin{array}{c}9.06 \\
(4.56)\end{array}$ & $\begin{array}{c}6.04 \\
(3.02) \\
\end{array}$ \\
\hline \multicolumn{6}{|c|}{ Panel C: Volatility } \\
\hline High & $\begin{array}{r}-102.24 \\
(-9.89)\end{array}$ & $\begin{array}{c}-46.99 \\
(-5.80)\end{array}$ & $\begin{array}{c}6.47 \\
(0.97)\end{array}$ & $\begin{array}{c}6.78 \\
(3.24)\end{array}$ & $\begin{array}{c}2.81 \\
(1.30)\end{array}$ \\
\hline Low & $\begin{array}{c}-45.76 \\
(-5.31)\end{array}$ & $\begin{array}{c}-26.40 \\
(-4.24)\end{array}$ & $\begin{array}{c}-4.26 \\
(-0.75)\end{array}$ & $\begin{array}{c}8.47 \\
(4.79) \\
\end{array}$ & $\begin{array}{c}6.29 \\
(3.49) \\
\end{array}$ \\
\hline \multicolumn{6}{|c|}{ Panel D: Analyst Coverage } \\
\hline High & $\begin{array}{c}-93.38 \\
(-9.76)\end{array}$ & $\begin{array}{c}-38.00 \\
(-4.97)\end{array}$ & $\begin{array}{c}6.10 \\
(0.90)\end{array}$ & $\begin{array}{c}7.15 \\
(3.71)\end{array}$ & $\begin{array}{c}3.85 \\
(1.98)\end{array}$ \\
\hline Low & $\begin{array}{l}-73.58 \\
(-7.59)\end{array}$ & $\begin{array}{l}-38.41 \\
(-5.35)\end{array}$ & $\begin{array}{c}-4.06 \\
(-0.70)\end{array}$ & $\begin{array}{c}8.27 \\
(4.50)\end{array}$ & $\begin{array}{c}4.76 \\
(2.54)\end{array}$ \\
\hline
\end{tabular}


stocks in their respective winner/size portfolios are grouped together as highIO stocks. Loser portfolios comprised of high-IO stocks and of low-IO stocks are formed analogously. Winner-minus-loser portfolios for high-IO stocks and for low-IO stocks can then be created, and are size-neutral.

Data on institutional ownership over 1983 to 2003 are from $13 \mathrm{~F}$ filings and come from Thomson Financial (CDA/Spectrum). Institutional ownership is defined as the percentage of each stock's outstanding shares that is held by institutional investors at the end of the quarter prior to week $t$. Using sizeneutral portfolios as described above, Panel B shows that stocks with lower institutional ownership produce greater momentum over weeks $[t+1, t+$ 52 ], with untabulated $t$-statistics exceeding 2.36 across the raw, CAPM, and Fama-French metrics. The finding that momentum is decreasing in institutional ownership is consistent with the joint hypothesis that momentum is due to mispricing and institutions are the more sophisticated, better-informed traders.

In Panel C, we measure return volatility as the standard deviation of returns over weeks $[t-52, t-1]$, where returns are again formed using the midpoints of the quoted bid and ask prices so that price movements due to bid-ask spreads are removed. Momentum is greater for low-volatility stocks $(t$-statistics testing the difference are at least 3.16 across the raw, CAPM, and Fama-French performance metrics and are not tabulated). This finding is the opposite of Zhang's (2006) 11-month finding that high-volatility stocks display greater momentum. To the extent that volatility captures uncertainty, 1-week momentum increases as uncertainty decreases.

Panel D of Table VII provides the profits of winner-minus-loser portfolios across high and low analyst coverage, using size-neutral portfolios as above. For each stock from 1983 to 2003, we obtain the number of analysts providing forecasts of future annual earnings from $\mathrm{I} / \mathrm{B} / \mathrm{E} / \mathrm{S}$ in the month prior to portfolio formation. Stocks with no coverage are excluded from this analysis, but the findings are unaffected when we include them. We find that stocks with low analyst coverage produce slightly higher mean profits over the 52-week window, the same direction as Zhang's (2006) finding using 11-month returns and Hong et al.'s (2000) finding using 6-month returns. However, the momentum differences across coverage are not statistically significant. The $t$-statistics testing the difference do not exceed 1.23 and are not shown. Thus, the prior findings that momentum is negatively related to analyst coverage are not robust across return horizons.

The characteristics examined in Table VII are not independent. For example, Gompers and Metrick (2001) and others provide evidence that institutions prefer to hold large stocks, Bhushan (1989) finds that stocks with greater analyst coverage are larger and have higher institutional ownership, and it is common knowledge that small stocks have greater return volatility. Therefore, to determine which of these effects if any dominates, we examine weekly crosssectional regressions, as in Table IV. Each week, we regress $r_{[t+1, t+52]}$ on $r_{t}$, the log of size, IO, return volatility, analyst coverage, and interactions of these four characteristics with $r_{t}$. The $\log$ of $\frac{B}{M}$ is also included as a control. Stocks with no analyst coverage are included in the regressions. The mean of the time 
series of coefficients on the interactions (multiplied by 100) and their associated $t$-statistics are as follows:

\begin{tabular}{lccc}
\hline Size $\times r_{t}$ & IO $\times r_{t}$ & Volatility $\times r_{t}$ & Coverage $\times r_{t}$ \\
\hline-4.95 & 0.65 & -162.11 & 0.43 \\
$(-4.73)$ & $(0.13)$ & $(-3.50)$ & $(1.78)$ \\
\hline
\end{tabular}

The regressions indicate that size, return volatility, and to a lesser extent, analyst coverage have separate effects on return momentum, whereas the effect of institutional ownership is subsumed by the other measures. ${ }^{20}$ Note that the positive coefficient on the analyst-coverage interaction differs slightly from the portfolio evidence in Table VII. This seems attributable to the omitted variables in the portfolio tests.

In sum, momentum in 1-week returns decreases with stock size and with return volatility. The effects of institutional ownership and analyst coverage on momentum are less clear. More importantly, these findings are mixed in their support for a positive relation between uncertainty and weekly momentum, and in the case of return volatility, are contradictory to the supposed relation.

There are also interesting results in Table VII with respect to short-run reversal. The week-1 reversal is statistically greater in large stocks, in highinstitutional-ownership stocks, in high-volatility stocks, and in high-analystcoverage stocks. Lehmann (1990) also identifies this large-firm effect in shortrun reversals. The finding that large, high-institutional-ownership, and highcoverage stocks experience greater short-run reversal might seem counterintuitive. Given that such stocks are typically associated with lower trading costs and illiquidity, with presumably a greater number of sophisticated traders, and with a better information environment, both the microstructure and overreaction explanations of short-run reversal seem less likely for such stocks.

As in the longer-run momentum case, we also estimate weekly cross-sectional regressions to examine the four short-run effects jointly. We regress $r_{t+1}$ on $r_{t}$, the log of size, IO, return volatility, analyst coverage, and interactions of these four characteristics with $r_{t}$, and we include the log of $\frac{B}{M}$ as a control. The mean of the time series of coefficients on the interactions (multiplied by 100) and their associated $t$-statistics are as follows:

\begin{tabular}{lccc}
\hline Size $\times r_{t}$ & IO $\times r_{t}$ & Volatility $\times r_{t}$ & Coverage $\times r_{t}$ \\
\hline-0.82 & -3.70 & -78.50 & -0.08 \\
$(-4.09)$ & $(-4.78)$ & $(-8.85)$ & $(-1.92)$ \\
\hline
\end{tabular}

${ }^{20}$ Serial correlation in the time series of coefficients on the interactions is not large in any case. The data-dependent number of lags used to estimate Gallant's (1987) robust standard errors, as discussed in Section III.B, vary only from two to five across these interaction coefficients. Despite the raw characteristics displaying strong persistence, the interactions do not; and consequently the test statistics on the interactions are reliable. 
The regressions show that the four effects on short-run reversal noted in the portfolio tests of Table VII are distinct. To not distract from the main focus of this study, which is the momentum in 1-week returns, we defer further discussion of short-run reversal to Section VII, where we provide additional short-run results as well as an overview of how our findings throughout this study affect the literature's view of short-run reversal.

\section{Discussion of the Possible Sources of Momentum}

What can possibly explain our finding of momentum in 1-week returns? In the preceding sections, we address several possibilities. The first is that momentum is attributable to the market's underreaction to explicit (public) news, which might be due to a combination of overconfidence and self-attribution bias or to a slow diffusion of information throughout the marketplace as Daniel et al. (1998) and Hong and Stein (1999), respectively, suggest. These two models also jointly predict an overreaction to implicit news. However, Table $\mathrm{V}$ is inconsistent with the notion that the market's reactions to explicit and implicit news are categorically different. Table V does find though that explicit news sparks greater momentum than implicit news, and implicit news generates greater short-run reversal. These differences in future returns suggest that further consideration of theories characterizing types of news and the market's potentially differing reactions to each type is warranted.

The second possibility we examine is a more general notion that psychological biases of some traders might be resulting in momentum. Zhang (2006) argues that if any psychological biases induce momentum, then uncertainty regarding a stock's valuation should intensify these biases and amplify the momentum in returns. The results presented in Sections IV.B and IV.C do not support this theory as a potential explanation of 1 -week momentum.

In addition, Table VII and the regression results noted in Section IV.C do not find that momentum in weekly returns increases as analyst coverage decreases. This seems inconsistent with Hong and Stein's (1999) proposition that slow diffusion of information contributes to momentum in returns.

On quite a different note, Grinblatt and Han (2005) argue that a disposition effect contributes to momentum, whereby traders hold loser stocks too long and sell winner stocks too soon, inducing underreaction to good and to bad news. This well-known disposition effect is motivated by a combination of prospect theory and mental accounting. Grinblatt and Han find that stocks with larger capital-gains overhang experience greater momentum. Moreover, they find that their capital-gains measure dominates 1-year return as a predictor of future returns. Frazzini (2006) extends the evidence for this theory to return momentum following earnings announcements. However, it seems unlikely that such a disposition effect is contributing to momentum in 1-week returns; we control for prior 6-month returns in Tables III and IV, and prior returns over such horizons should be a (noisy) proxy for capital-gains overhang.

Recently, Grinblatt and Moskowitz (2004) and Watkins (2003) document that return consistency contributes to momentum in 6- to 12-month returns. Specifically, stocks with a high frequency of positive returns over the prior 6 
or 12 months have higher future returns, and stocks with a high frequency of negative returns have lower future returns. Grinblatt and Moskowitz cite several possible interpretations of these consistency effects, including information diffusion and the capital-gains-overhang (disposition) effect. Later in Section VI, we examine short-run consistency in returns. For now, we note that we find no evidence that return consistency contributes to momentum in 1-week (or 4-week) returns.

Lastly, we wish to highlight that rational theories of momentum (not involving misspecified factor risks) also exist. Lewellen and Shanken (2002), Brav and Heaton (2002), and Veronesi (1999) show how rational learning can induce momentum and reversal in returns. While these and other theoretical papers provide intriguing, and to our view, reasonable possibilities, we are aware of no empirical test of these rational learning theories. In fact, Brav and Heaton point out how difficult it is for current empirics to distinguish between behavioral and rational explanations, as they both predict similar patterns in returns. Further consideration of such rational theories is warranted as well.

\section{Robustness Considerations}

We now turn our attention to robustness checks regarding the evidence of momentum in 1-week returns. First, we consider an alternative specification of the calendar-time method that allows for heteroskedasticity in the time series of portfolio profits and for variations in portfolio factor loadings. Second, we examine transaction prices to estimate returns instead of the midpoint of the bid and ask quotes. The transaction data go back to 1963 and greatly extend our testing period, which begins in 1983 using the quote data. Third, we provide the pre-formation profits to the extreme-return winner-minus-loser portfolios and show that positive profits are not present before week $t$. This finding allays potentially lingering concerns that we are identifying momentum profits in the post-formation period due to misspecification of the model of expected returns for these portfolios. Last, we show that momentum is detected in 1-month (4-week) returns as well.

\section{A. Alternative Method to Accommodate Possible Heteroskedasticity and Varying Factor Loadings}

When employing the calendar-time methods of the preceding sections, two potential concerns arise from the weekly changes in the composition of the portfolios. The first is that the variance in a portfolio's profits can change over time. The second is that the loadings on the factors in the CAPM and Fama-French models can change over time. Readers might wonder if the procedures employed above fully accommodate these potential issues. To address this question, we examine an alternative testing procedure advocated by Mitchell and Stafford (2000) and others. Our findings are similar whether we use the methods above or the alternative we detail here.

Taking advantage of the data available on the individual stocks that comprise a portfolio in a given week, we accommodate potential time-series dynamics 
in the variance of the portfolio's profits and in the portfolio's factor loadings. Each calendar week $\tau$, we identify the stocks in the winner and loser portfolios. Then, using only those specific stocks, we estimate the given winner-minusloser portfolio's abnormal returns over the $[\tau+1, \tau+52]$ period. In the CAPM and Fama-French specifications, the abnormal return for week $\tau$ is calculated using the estimated portfolio loadings over $[\tau+1, \tau+52]$ and the factor realizations in week $\tau$. Re-estimating the factor loadings for each week's portfolio allows loadings to change each calendar week as the composition of the portfolio changes.

To control for possible heteroskedasticity, the standard deviation of the profits to each week's portfolio is estimated using the profits over $[\tau+1, \tau+$ 52]. The abnormal return of the portfolio in week $\tau$ is divided by its standard deviation. This procedure is repeated each calendar week to obtain a time series of standardized abnormal returns whose variance should be constant (one).

The outcome of this procedure is a time series of profits that accommodates heteroskedasticity and variations in factor loadings. Our findings that momentum exists in 1-week returns as well as the various findings on interactions with momentum are robust when using this alternative procedure, and are not tabulated.

\section{B. Transaction Returns and Extended Time Period}

We replace our initial sample of midpoint returns from 1983 to 2003 with transaction returns formed using Wednesdays' closing transaction prices from CRSP for all stocks from 1963 to 2003. The advantage of using midpoint returns is that we eliminate the spurious reversal due to bid-ask bounce. Using transaction returns allows us to examine the robustness of our findings. Specifically, we examine whether the momentum discovered after week $t+3$ is strong enough to offset the early reversal even when bid-ask bounce is included.

Table VIII reports the performances of the extreme winner-minus-loser portfolio using transaction returns from 1963 to 2003 over various holding periods. The procedure in Table VIII is the same as that in Table I save that transactionbased returns are used. As expected, the reversal in week $t+1$ is much stronger using transaction returns with profits roughly twice as large as those formed using midpoint returns in Table I. Nevertheless, the last column of Table VIII shows that the finding of momentum in weekly returns is robust when using transaction returns and when extending the sample period back to 1963. Profits remain significantly positive over $[t+1, t+52]$.

\section{Pre-formation Performance}

We examine the pre-formation performance of extreme-return stocks to address the concern that our modeling of expected stock returns is misspecified, that is, the concern that the results in Table I are due not to momentum in 


\section{Table VIII}

\section{Profits to Weekly Portfolios Using Transaction Returns (Winners minus Losers)}

Each week from July 1963 to 2003, we rank stocks based on their returns over the week and form a portfolio comprised of a long position in the top decile of stocks (winners) and a short position in the bottom decile (losers). Returns are formed from closing transaction prices. Stocks priced below five dollars at the end of formation week $t$ are excluded. Calendar-time alphas are estimated over various holding periods using raw returns, the CAPM, and the Fama-French three-factor model. The $t$-statistics are in parentheses and are robust to heteroskedasticity and autocorrelation. Profits are in basis points.

\begin{tabular}{lccccc}
\hline & \multicolumn{5}{c}{ Holding Period } \\
\cline { 2 - 5 } & Week & Week & Week & Weeks & Weeks \\
& 1 & 2 & 3 & $4-52$ & $1-52$ \\
\hline \multirow{2}{*}{ Raw } & -132.13 & -42.92 & -8.00 & 6.48 & 2.49 \\
CAPM & $(-30.98)$ & $(-11.32)$ & $(-2.55)$ & $(6.55)$ & $(2.47)$ \\
Fama-French & -129.77 & -40.68 & -6.71 & 6.79 & 2.89 \\
& $(-31.59)$ & $(-11.06)$ & $(-2.15)$ & $(7.37)$ & $(3.14)$ \\
& -130.21 & -40.33 & -7.07 & 6.89 & 2.96 \\
& $(-30.32)$ & $(-10.83)$ & $(-2.25)$ & $(6.84)$ & $(2.92)$ \\
\hline
\end{tabular}

Table IX

\section{Pre-formation Profits to Weekly Extreme Portfolios (Winners minus Losers)}

Each week from 1983 to 2003, we rank stocks based on their returns over the week and form a portfolio comprised of a long position in the top decile of stocks (winners) and a short position in the bottom decile (losers). Returns are formed from the midpoints of the quoted bid and ask prices at each day's close. Stocks priced below five dollars at the end of formation week $t$ are excluded. Calendar-time alphas are estimated over various pre-formation windows from week $t-52$ to week $t-1$ using raw returns, the CAPM, and the Fama-French three-factor model. The $t$-statistics are in parentheses and are robust to heteroskedasticity and autocorrelation. Profits are in basis points.

\begin{tabular}{lcccc}
\hline & \multicolumn{4}{c}{ Holding Period } \\
\cline { 2 - 5 } & Weeks & Week & Week & Week \\
& -52 to -4 & -3 & -2 & -1 \\
\hline \multirow{2}{*}{ Raw } & 0.07 & -6.29 & -50.08 & -94.53 \\
CAPM & $(0.05)$ & $(-1.15)$ & $(-7.72)$ & $(-10.56)$ \\
Fama-French & 1.03 & -5.60 & -50.45 & -93.67 \\
& $(0.84)$ & $(-1.02)$ & $(-7.47)$ & $(-10.45)$ \\
& -0.81 & -6.75 & -50.21 & -93.18 \\
& $(-0.65)$ & $(-1.19)$ & $(-7.79)$ & $(-10.88)$ \\
\hline
\end{tabular}

returns in week $t$ but to an inherent (priced) characteristic of the selected stocks that we fail to capture. Table IX reports the performances of the extreme-return winner-minus-loser portfolio (as in Table I) over various pre-formation windows. None of the windows from week $t-52$ to week $t-1$ display momentum profits. Hence, momentum profits in the 52 -week post-formation window are not due to a persistent misspecification of expected returns. 


\section{Table X \\ Profits to Monthly Extreme Portfolios \\ (Winners minus Losers)}

Each week from 1983 to 2003, we rank stocks based on their returns over weeks $[t-3, t]$ and form a portfolio comprised of a long position in the top decile of stocks (winners) and a short position in the bottom decile (losers). Returns are formed from the midpoints of the quoted bid and ask prices at each day's close. Stocks priced below five dollars at the end of the formation week $t$ are excluded. Calendar-time alphas are estimated over various holding periods using raw returns, the CAPM, and the Fama-French three-factor model. The $t$-statistics are in parentheses and are robust to heteroskedasticity and autocorrelation. Profits are in basis points.

\begin{tabular}{lccccc}
\hline & \multicolumn{5}{c}{ Holding Period } \\
\cline { 2 - 6 } & Week & Week & Week & Weeks & Weeks \\
& 1 & 2 & 3 & $4-52$ & $1-52$ \\
\hline \multirow{2}{*}{ Raw } & -61.41 & -16.51 & 8.12 & 15.65 & 13.18 \\
CAPM & $(-6.15)$ & $(-2.01)$ & $(1.17)$ & $(4.55)$ & $(3.78)$ \\
Fama-French & -54.50 & -11.41 & 11.82 & 15.79 & 13.63 \\
& $(-5.90)$ & $(-1.46)$ & $(1.65)$ & $(4.75)$ & $(4.08)$ \\
& -58.94 & -15.63 & 8.00 & 16.54 & 14.10 \\
& $(-5.94)$ & $(-1.83)$ & $(1.05)$ & $(4.69)$ & $(3.91)$ \\
\hline
\end{tabular}

Interestingly, Table IX does show negative profits in weeks $t-1$ and $t-2$. This pre-formation reversal in returns is the mirror image of the post-formation reversal. ${ }^{21}$ This finding suggests that the forces that induce reversal in returns across weeks $t$ to $t+1$ also induce reversal across weeks $t-1$ to $t$. As noted earlier, two potential explanations of the reversal are microstructure issues and traders' overreaction to news. In Section VII we discuss what our findings as a whole can and cannot say about the short-run reversal.

\section{Momentum in 1-Month Returns}

For completeness, we also examine whether momentum exists in 1-month returns. Jegadeesh (1990) finds that short-run reversal in returns occurs at the 1-month horizon, not just the 1-week horizon documented by Lehmann (1990). We rank stocks each week based on returns over $[t-3, t]$ and define winner stocks to be those in the top decile of returns over that 4-week period and loser stocks to be those in the bottom decile over that 4-week period.

Table $\mathrm{X}$ provides the profits to the winner-minus-loser portfolio over various holding periods. Consistent with Jegadeesh's (1990) results, we see that 4-week returns reverse strongly in week $t+1$. As with 1 -week returns (in Table I), the reversal dies out quickly and is completely gone by week $t+3$. The 4 -week extreme portfolio then displays a run-up in profits over weeks $[t+4, t+52]$, and this run-up is once again strong enough to offset the initial reversal and generate statistically significant momentum profits over weeks $[t+1, t+52]$, with $t$-statistics greater than 3.7 across raw, CAPM, and Fama-French performance

\footnotetext{
${ }^{21}$ Ball et al. (1995) find similar results using bid-to-bid returns on NASDAQ stocks from 1983 to 1990 .
} 
metrics. In short, portfolios based on 4-week returns behave qualitatively the same as portfolios based on 1-week returns.

\section{Return Consistency}

Grinblatt and Moskowitz (2004) and Watkins (2003) find that stocks with a high frequency of positive returns over the past 6 to 36 months have higher returns than other stocks, and Watkins finds that stocks with a high frequency of negative returns over these long horizons have lower returns than other stocks. ${ }^{22}$ These researchers also show that a portion of the momentum in 6- and 12-month returns is related to these return-consistency effects. In addition, Watkins (2006) examines short-run consistency over 2 and 4 weeks and finds that positive consistency leads to lower returns the next week and negative consistency leads to higher returns the next week.

We extend this related literature and examine whether return consistency over 1 and 4 weeks contributes to the momentum in returns that we document in prior sections. We define a stock to be positively consistent in week $t$ if it has 5 days of raw returns greater than zero and negatively consistent in week $t$ if it has 5 days of raw returns less than zero. Our choice of 5 out of 5 days to define consistency reflects our belief that 4 out of 5 might not be restrictive enough. Grinblatt and Moskowitz (2004) select proportions of periods that have roughly $10 \%$ probability under a binomial distribution assuming 0.5 probability of positive and nonpositive returns (or negative and nonnegative) each period. The probability of 5 out of 5 is roughly $3 \%$, while the probability of at least 4 out of 5 is roughly $19 \%$.

For the 4-week formation period over weeks $[t-3, t]$, we define positive consistency to be at least $70 \%$ of the available days. For nonholiday periods, this requires at least 14 of the 20 days to be consistently positive or negative, which occurs under the binomial distribution with probability $6 \%$ and is the specification used by Watkins (2006).

In this section we rely exclusively on cross-sectional regressions to examine the ability of return consistency over weekly and monthly horizons to predict future returns. Portfolio methods, as it turns out, do not adequately control for prior returns when conditioning on return consistency. For example, after identifying winner and loser stocks in week $t$ based on sorting raw returns into deciles, we find that the mean return spread between 1-week consistent winners and losers in formation week $t$ is $27 \%$ over 1983-2003; the spread between nonconsistent winners and losers is only $22 \%$. The $5 \%$ difference in returns in the formation week should generate a significant momentum effect that spuriously would be attributed to a consistency effect. As evidence of this, the less-extreme portfolio (8-3) in Table II has a $5.2 \%$ return spread in the formation week, and we detect momentum profits over weeks $[t+1, t+52]$

\footnotetext{
${ }^{22}$ The source of the divergence in Grinblatt and Moskowitz's (2004) and Watkins's (2003) findings regarding loser consistency is unclear, but is possibly due to the different methods used by each to control for other known effects on stock returns.
} 
for that portfolio. We therefore conclude that the portfolio method does not adequately control for formation-week returns when conditioning on consistency. Hence, we use regressions.

Each week $t$, we regress the cross-section of return over $[t+1, t+52]$ on a consistency dummy variable defined over either week $t$ or weeks $[t-3, t]$, the corresponding return over either week $t$ or weeks $[t-3, t]$, and the logs of size and $\frac{B}{M}$. The weekly time series of coefficients is then used to test the null hypothesis that each coefficient is zero. See Section III.B for details on the robust standard errors. We define the consistency dummy variable (CONS) as

$$
\text { CONS }_{i t}{ }^{h}=\left\{\begin{aligned}
1 & \text { if stock } i \text { is positively consistent over horizon } h \\
-1 & \text { if stock } i \text { is negatively consistent over horizon } h \\
0 & \text { otherwise, }
\end{aligned}\right.
$$

where $h=($ Week, Mth), which indicates whether consistency is determined over week $t$ or over weeks $[t-3, t]$. We choose to combine the potential effects of positive and negative consistency into a single dummy variable for brevity, since we find that little information is lost by reporting the single measure. We also examine the return over $t+1$ as the dependent variable for completeness. In addition, for a given calendar week to be included in the analysis, we require at least 10 stocks that week to be labeled positively consistent and 10 stocks to be labeled negatively consistent. ${ }^{23}$

Table XI reports the results of the cross-sectional regression analyses. Panels $A$ and $B$ respectively show that Cons $t_{t}^{\text {Week }}$ is not related to either the return over week $t+1$ or the return over weeks $[t+1, t+52]$, controlling for $\frac{B}{M}$, size, and the formation-period return. Thus, consistency measured over the shortest window of 5 days does not display an ability to predict future returns. ${ }^{24}$ Panel $\mathrm{C}$ shows that Cons $s_{t}^{\text {Mth }}$ is negatively related to returns in week $t$, consistent with Watkins's (2006) short-run finding. Specifically, the mean profit in week $t+$ 1 to buying stocks that were positively consistent over the past 4 weeks and shorting the stocks that were negatively consistent is $-0.42 \%(=-0.21 \% \times 2)$. However, Panel D shows that Cons $_{t}^{M t h}$ is not related to longer-run performance over weeks $[t+1, t+52]$.

In short, while 4-week consistency is related to return reversal in the subsequent week, we find that consistency in returns does not contribute to our findings of longer-run momentum in 1- and 4-week returns.

\section{Short-Run Reversal}

In addition to finding return momentum in a seemingly unexpected placeweekly returns-our results shed new light on short-run reversal. First, reversal in returns is less prevalent than prior studies indicate. After eliminating

\footnotetext{
${ }^{23}$ The minimum number of weeks available for analysis across the various specifications of regressions is 580 .

${ }^{24}$ Separating the consistency dummy variable into its positive and negative components finds a negative relation between negative consistency in week $t$ and return in week $t+1$.
} 
Table XI

\section{Effects of Return Consistency}

Each week from 1983 to 2002, we regress the cross-section of various future holding-period returns on return consistency, formation-period return, $\frac{B}{M}$, and size. A stock is positively consistent last week if it has positive returns for 5 out of 5 days in week $t$. A stock is positively consistent last month if it has positive returns at least 14 out of 20 days in weeks $[t-3, t]$. Negative consistency is defined analogously for the prior week and the prior month. $C O N S_{t}^{h}$ is set to one if a stock is positively consistent in the prior period, to negative one if a stock is negatively consistent, or to zero otherwise, where $h=$ (week, month). The mean of the weekly time series of each coefficient is reported below and is tested to be zero. The $t$-statistics are in parentheses and are robust to heteroskedasticity and autocorrelation. The mean coefficients on the return consistency measures are given in column 1 . The mean coefficients of the return over week $t$ and over weeks $[t-3, t]$ are given analogously in column 2 . The log of the book-to-market ratio (column 4) and size (column 5) are included as controls and are updated the first week in January and the first week in July, respectively, and are sampled at week $t$. Returns are formed from the quoted bid and ask prices at each day's close. Stocks priced below five dollars at the end of the week from which the 1-week return is sampled are excluded. Reported coefficient estimates are multiplied by 100 .

\begin{tabular}{lcccc}
\hline & \multicolumn{1}{c}{1} & \multicolumn{1}{c}{3} & 4 \\
\cline { 2 - 5 } Future Return & \multicolumn{4}{c}{ Explanatory Variables } \\
\hline A. $r_{t+1}$ & Cons $_{t}^{\text {Week }}$ & $r_{t}$ & $\ln \left(\frac{B}{M}\right)$ & $\ln ($ size $)$ \\
\cline { 2 - 5 } & -0.06 & -4.04 & 0.31 & 0.04 \\
& $(-1.10)$ & $(-7.86)$ & $(7.15)$ & $(2.37)$ \\
B. $r_{[t+1, t+52]}$ & Cons $_{t}^{\text {Week }}$ & $r_{t}$ & $\ln \left(\frac{B}{M}\right)$ & $\ln ($ size $)$ \\
\cline { 2 - 5 } & -0.14 & 11.55 & 9.09 & 0.53 \\
C. $r_{t+1}$ & $(-0.42)$ & $(4.61)$ & $(6.25)$ & $(0.92)$ \\
& Cons $s_{t}^{M t h}$ & $r_{[t-3, t]}$ & $\ln \left(\frac{B}{M}\right)$ & $\ln ($ size $)$ \\
\cline { 2 - 5 } & -0.21 & -1.46 & 0.31 & 0.02 \\
D. $r_{[t+1, t+52]}$ & $(-4.63)$ & $(-6.22)$ & $(6.16)$ & $(1.39)$ \\
& Cons $s_{t}^{\text {Mth }}$ & $r_{[t-3, t]}$ & $\ln \left(\frac{B}{M}\right)$ & $\ln ($ size $)$ \\
\cline { 2 - 5 } & 0.15 & 15.38 & 8.59 & 0.10 \\
& $(0.23)$ & $(3.22)$ & $(5.13)$ & $(0.13)$ \\
\hline
\end{tabular}

bid-ask bounce, week-1 reversals are limited to extreme-return stocks (Table II). Second, and more importantly, reversal is not the largest effect in 1-week returns; momentum is. Returns over $[t+1, t+52]$ are positively related to returns in week $t$ despite the brief reversal in weeks $t+1$ and $t+2$ (Tables I and IV).

There are at least two categories of explanations for this complex return pattern. The first is that price-setting trading behaviors are more heterogeneous than previously thought. For example, short-term traders might overreact to news and longer-term traders might underreact. Or, all traders might overreact to a short-lived and extreme piece of information, yet underreact to a longer-lived and more value-relevant piece of information. A second category of explanations involves short-run reversal being due solely to illiquidity and not to overreaction. Specifically, traders might underreact to news in general, driving the momentum in returns, yet sufficient price pressure might build 
during the news release to drive a brief reversal.

We offer no evidence to distinguish these two categories of possibilities, that is, to either verify or eliminate overreaction as a determinant of short-run reversal. However, we provide additional evidence of illiquidity as a contributor to short-run reversal. As Subrahmanyam (2005) notes, a necessary condition for illiquidity/microstructure to account for return reversal is for order imbalance to relate negatively to future returns. Subrahmanyam does not find any relation between order imbalance and monthly returns, but the monthly horizon he uses might be too long. We reexamine that relation at the weekly frequency.

Using ISSM and TAQ data on NYSE stocks, we examine the relation between order imbalance and next week's return. We sign trades using Lee and Ready's (1991) procedure. Trades executing above (below) the prevailing quote midpoint are categorized as buys (sells). For trades executing at the midpoint, those following an uptick (downtick) are categorized as buys (sells). Following Bessembinder (2003), we assume quotes are recorded with a 5-second delay until 1998 and that they are recorded instantaneously thereafter. Dollar order imbalance in week $t, O \operatorname{Im} b_{t}$, is the dollar value of buy orders less the dollar value of sell orders.

We then examine weekly cross-sectional regressions of $r_{t+1}$ on $O \operatorname{Im} b_{t}$. Following Subrahmanyam (2005), we include trading volume in week $t$ as a control. The mean of the time series of coefficients on $O \mathrm{Imb}_{t}$ from January 1983 to December 2003 (multiplied by $10^{10}$ ) is -0.21 and is significantly negative with a $t$-statistic of -4.32 . However, the inclusion of $r_{t}$ removes the negative relation of $O \operatorname{Im} b_{t}$ with $r_{t+1}$.

Our only point with respect to these regressions is to establish that illiquidity is an empirically plausible explanation of short-run reversal at weekly horizons. Using Amihud's (2002) measure of illiquidity, Avramov et al. (2006) suggest the same. How much of the explanatory power of $r_{t}$ is actually due to illiquidity remains a contested issue as currently available microstructure measures do not fully capture return reversal. ${ }^{25}$

Kaniel, Saar, and Titman (2004) offer an interesting new perspective on illiquidity and short-run reversal. They find that individuals are contrarian investors over weekly horizons and suggest that individuals provide liquidity to institutions who demand immediacy in their trades. Their conjecture implies that order flow and inventory measures need to account for the role of individuals as liquidity providers. In addition, because the trading activity of institutions is greater in the stocks in which institutions hold more shares (as shown by Boehmer and Kelley (2005)), the greater short-run reversal in large, high-coverage, and high-institutional-ownership stocks in Table VII might be due to greater demand for immediacy by institutional traders. Further analysis of the behavior of institutional traders would be an interesting avenue for future research. One last point in this regard is that, if institutions are demanding immediacy and incurring trading costs, our momentum findings over weeks

\footnotetext{
${ }^{25}$ On this note, Hendershott and Seasholes (2006) provide complementary cross-sectional evidence that the weekly inventory of the NYSE specialist relates positively to next week's return. They also find that inventory and order imbalance remain significant determinants of $r_{t+1}$ in the presence of $r_{t}$. However, $r_{t}$ remains significant as well.
} 
$[t+1, t+52]$ suggest that on net institutions do not suffer if stocks are held for the entire year, as the benefit of return momentum offsets the presumed costs of immediacy.

In short, neither the reversal nor the momentum that follows extreme weekly returns is fully understood. To the extent that weekly returns contain traders' misreactions to news, we can conclude that overreaction is not the largest misreaction; rather, underreaction is. ${ }^{26}$

\section{Conclusion}

A portfolio that buys last week's winner stocks and shorts last week's loser stocks earns positive profits over the next 52 weeks. This is striking given the well-known presence of negative (contrarian) profits in the first weeks following an extreme weekly return. Thus, a literature that once portrayed weekly returns only as reversing must now recognize a second effect, momentum, which offsets and indeed dominates the reversal.

The finding of momentum in 1-week returns, which complements the findings of momentum in corporate events, firm-specific headline news, and longer-run returns up to 12 months, simplifies the anomaly picture, as return continuation is a pervasive phenomenon. Moreover, weekly returns provide researchers a new and more stringent testing ground of momentum theories. For example, revisiting the studies by Chan (2003) and Zhang (2006), we find that their longer-run momentum results do not extend to 1-week momentum. Specifically, we find that the market's reactions to explicit news (price movements associated with public news) and to implicit news (price movements without public news) are not categorically different, and that uncertainty is not related to momentum in 1-week returns. Interestingly though, return momentum following explicit news is stronger than return momentum following implicit news. Further examinations of this finding might be fruitful.

In addition to the finding of longer-run momentum following weekly returns, we find that winner and loser stocks outside the extreme deciles of weekly returns generate momentum profits in the subsequent week. In short, momentum is the dominant effect in weekly returns. If abnormal profits are due to the market's misreactions to news, then on net, weekly returns seem better characterized as underreactions, not overreactions.

\section{REFERENCES}

Amihud, Yakov, 2002, Illiquidity and stock returns: Cross-section and time-series effects, Journal of Financial Markets 5, 31-56.

Andrews, Donald W. K., 1991, Heteroskedastic and autocorrelation consistent covariance matrix estimation, Econometrica 59, 817-858.

Avramov, Doron, Tarun Chordia, and Amit Goyal, 2006, Liquidity and autocorrelations in individual stock returns, Journal of Finance 61, 2365-2394.

${ }^{26}$ When we extend the holding-period window in Table I to 3 years following extreme weekly returns, profits are no longer statistically different from zero. The interpretation that extreme weekly returns are better viewed as underreactions is then tempered, but the evidence that extreme weekly returns are not too extreme remains, which is still a notable departure from prior studies. 
Ball, Ray, S.P. Kothari, and Charles E. Wasley, 1995, Can we implement research on stock trading rules? Journal of Portfolio Management 21, 54-63.

Barberis, Nicholas, Andrei Shleifer, and Robert Vishny, 1998, A model of investor sentiment, Journal of Financial Economics 49, 307-343.

Bessembinder, Hendrick, 2003, Issues in assessing trade execution costs, Journal of Financial Markets 6, 233-257.

Bhushan, Ravi, 1989, Firm characteristics and analyst following, Journal of Accounting and Economics 11, 255-274.

Boehmer, Ekkehart, and Eric Kelley, 2005, Institutional investors and the informational efficiency of prices, Working paper, Texas A\&M University.

Boudoukh, Jacob, Matthew P. Richardson, and Robert F. Whitelaw, 1994, Tale of three schools: Insights on autocorrelations of short-horizon stock returns, Review of Financial Studies 7 , 539-573.

Brav, Alon, and J. B. Heaton, 2002, Competing theories of financial anomalies, Review of Financial Studies 15, 575-606.

Chan, Wesley S., 2003, Stock price reaction to news and no-news: Drift and reversal after headlines, Journal of Financial Economics 70, 223-260.

Conrad, Jennifer S., Allaudeen Hameed, and Cathy Niden, 1994, Volume and autocovariances in short-horizon individual security returns, Journal of Finance 49, 1305-1329.

Conrad, Jennifer, Gautam Kaul, and M. Nimalendran, 1991, Components of short-horizon individual security returns, Journal of Financial Economics 29, 365-384.

Cooper, Michael, 1999, Filter rules based on price and volume in individual security overreaction, Review of Financial Studies 12, 901-935.

Daniel, Kent, David Hirshleifer, and Avanidhar Subrahmanyam, 1998, Investor psychology and investor security market under- and overreactions, Journal of Finance 53, 1839-1886.

Daniel, Kent, and Sheridan Titman, 2006, Market reactions to tangible and intangible information, Journal of Finance 61, 1605-1643.

DeBondt, Werner F.M., and Richard Thaler, 1985, Does the stock market overreact? Journal of Finance 40, 793-808.

Diether, Karl B., Christopher J. Malloy, and Anna Scherbina, 2002, Differences of opinion and the cross-section of stock returns, Journal of Finance 57, 2113-2141.

Fama, Eugene F., 1998, Market efficiency, long-term returns, and behavioral finance, Journal of Financial Economics 49, 283-306.

Frazzini, Andrea, 2006, The disposition effect and underreaction to news, Journal of Finance 61, 2017-2046.

Gallant, A. Ronald, 1987, Nonlinear Statistical Models (John Wiley and Sons, New York).

Gompers, Paul A., and Andrew Metrick, 2001, Institutional investors and equity prices, Quarterly Journal of Economics 116, 229-259.

Grinblatt, Mark, and Bing Han, 2005, Prospect theory, mental accounting and momentum, Journal of Financial Economics 78, 311-333.

Grinblatt, Mark, and Tobias J. Moskowitz, 2004, Predicting stock price movements from past returns: The role of consistency and tax-loss selling, Journal of Financial Economics 71, 541-579.

Grundy, Bruce D., and Spencer J. Martin, 2001, Understanding the nature of the risks and the sources of the rewards to momentum investing, Review of Financial Studies 14, 29-78.

Hansch, Oliver, Narayan Y. Naik, and S. Viswanathan, 1998, Do inventories matter in dealership markets? Evidence from the London Stock Exchange, Journal of Finance 53, 1623-1656.

Hasbrouck, Joel, and George Sofianos, 1993, The trades of market makers: An empirical analysis of NYSE specialists, Journal of Finance 48, 1565-1593.

Hendershott, Terrence, and Mark S. Seasholes, 2006, Specialist inventories and stock prices, Working paper, University of California, Berkeley.

Hirshleifer, David, 2001, Investor psychology and asset pricing, Journal of Finance 56, 1533-1597.

Hong, Harrison, Terence Lim, and Jeremy C. Stein, 2000, Bad news travels slowly: Size, analyst coverage, and the profitability of momentum strategies, Journal of Finance 55, 265-295.

Hong, Harrison, and Jeremy C. Stein, 1999, A unified theory of underreaction, momentum trading, and overreaction in asset markets, Journal of Finance 54, 2143-2184. 
Jegadeesh, Narasimhan, 1990, Evidence of predictable behavior of security returns, Journal of Finance 45, 881-898.

Jegadeesh, Narasimhan, and Sheridan Titman, 1993, Returns to buying winners and selling losers: Implications for market efficiency, Journal of Finance 48, 65-92.

Jegadeesh, Narasimhan, and Sheridan Titman, 1995a, Overreaction, delayed reaction, and contrarian profits, Review of Financial Studies 8, 973-993.

Jegadeesh, Narasimhan, and Sheridan Titman, 1995b, Short-horizon return reversals and the bid-ask spread, Journal of Financial Intermediation 4, 116-132.

Johnson, Timothy C., 2004, Forecast dispersion and the cross-section of expected returns, Journal of Finance 59, 1957-1978.

Kaniel, Ron, Gideon Saar, and Sheridan Titman, 2004, Individual investor sentiment and stock returns, Working paper, Duke University.

Kaul, Gautam, and M. Nimalendran, 1990, Price reversals: Bid-ask errors or market overreaction? Journal of Financial Economics 28, 67-93.

Lee, Charles M.C., and Mark Ready, 1991, Inferring trade direction from inter-day data, Journal of Finance 46, 733-746.

Lehmann, Bruce N., 1990, Fads, martingales, and market efficiency, Quarterly Journal of Economics $105,1-28$.

Lewellen, Jonathan, and Jay Shanken, 2002, Learning, asset-pricing tests, and market efficiency, Journal of Finance 57, 1113-1145.

Lo, Andrew W., and A. Craig MacKinlay, 1990, When are contrarian profits due to stock market overreaction? Review of Financial Studies 3, 175-205.

Madhavan, Ananth, and Seymour Smidt, 1993, An analysis of changes in specialists inventories and quotations, Journal of Finance 48, 1595-1628.

Mitchell, Mark L., and Erik Stafford, 2000, Managerial decisions and long-term stock price performance, Journal of Business 73, 287-329.

Payne, Jeff L., and Wayne B. Thomas, 2003, The implications of using stock-split adjusted I/B/E/S data in empirical research, Accounting Review 78, 1049-1067.

Roll, Richard, 1984, A simple implicit measure of the effective bid-ask spread in an efficient market, Journal of Finance 39, 1127-1139.

Subrahmanyam, Avanidhar, 2005, Distinguishing between rationales for short-horizon predictability in stock returns, Financial Review 40, 11-35.

Veronesi, Pietro, 1999, Stock market overreaction to bad news in good times: A rational expectations equilibrium model, Review of Financial Studies 12, 975-1007.

Veronesi, Pietro, 2000, How does information quality affect stock returns? Journal of Finance 50, 807-837.

Watkins, Boyce, 2003, Riding the wave of sentiment: An analysis of consistency as a predictor of future returns, Journal of Behavioral Finance 4, 191-200.

Watkins, Boyce, 2006, Institutional ownership and return reversals following short-term return consistency, Financial Review 41, 435-448.

Zhang, X. Frank, 2006, Information uncertainty and stock returns, Journal of Finance 61, 105-137. 